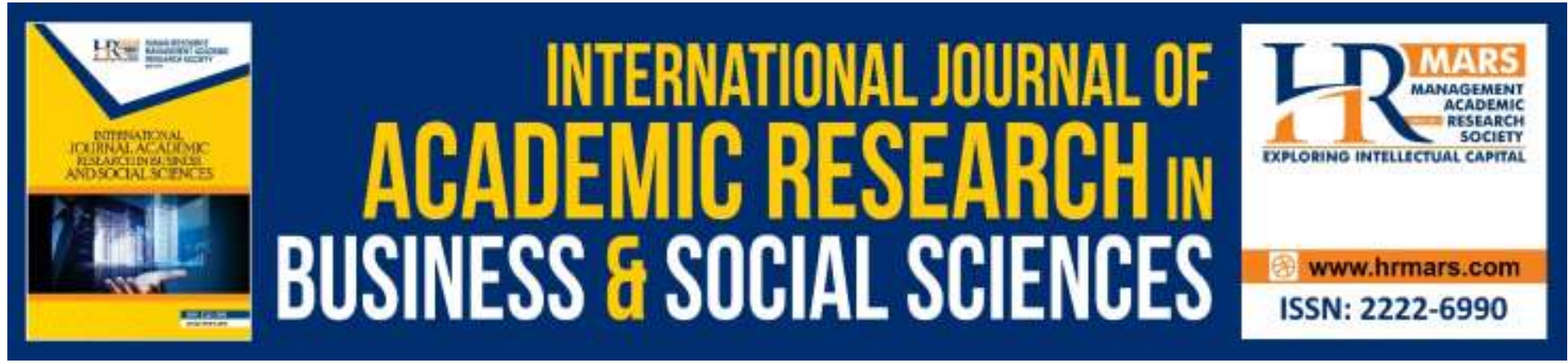

\title{
Online Counseling as an Alternative of New Millennial Helping Services
}

\author{
Hafizah Mejah, Abu Yazid Abu Bakar \& Salleh Amat
}

To Link this Article: http://dx.doi.org/10.6007/IJARBSS/v9-i9/6267

DOI: $10.6007 /$ IJARBSS/v9-i9/6267

Received: 08 June 2019, Revised: 19 July 2019, Accepted: 29 August 2019

Published Online: 08 September 2019

In-Text Citation: (Mejah, Bakar, \& Amat, 2019)

To Cite this Article: Mejah, H., Bakar, A. Y. A., \& Amat, S. (2019). Online Counseling as an Alternative of New Millennial Helping Services. International Journal of Academic Research in Business and Social Sciences, 9(9), 40-54.

Copyright: (C) 2019 The Author(s)

Published by Human Resource Management Academic Research Society (www.hrmars.com)

This article is published under the Creative Commons Attribution (CC BY 4.0) license. Anyone may reproduce, distribute, translate and create derivative works of this article (for both commercial and non-commercial purposes), subject to full attribution to the original publication and authors. The full terms of this license may be seen at: http://creativecommons.org/licences/by/4.0/legalcode

\section{Vol. 9, No. 9, 2019, Pg. 40 - 54}

Full Terms \& Conditions of access and use can be found at http://hrmars.com/index.php/pages/detail/publication-ethics 


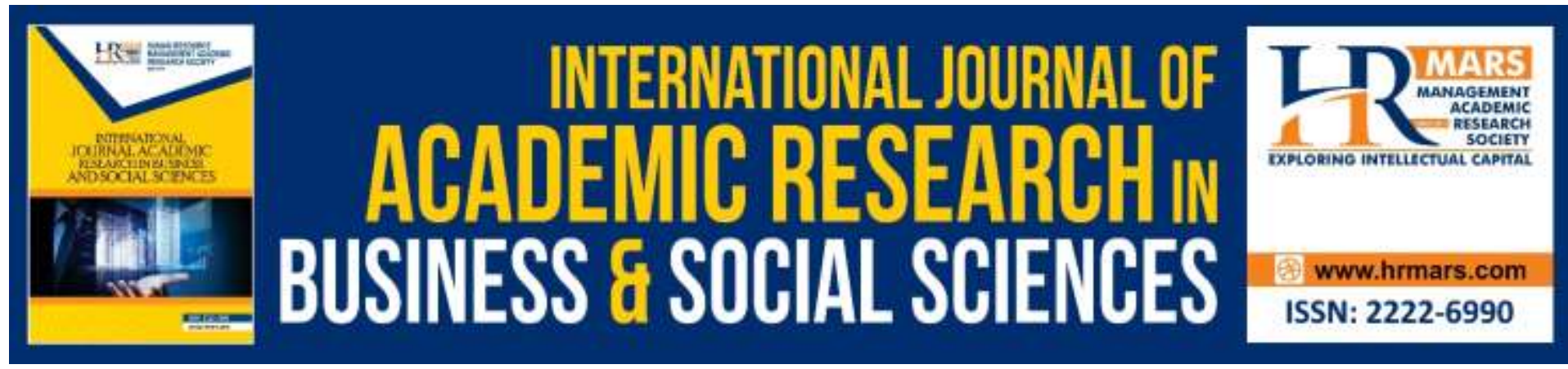

\title{
Online Counseling as an Alternative of New Millennial Helping Services
}

\author{
Hafizah Mejah, Abu Yazid Abu Bakar \& Salleh Amat \\ Faculty of Education, Universiti Kebangsaan Malaysia, 43600 UKM Bangi, Selangor, \\ Malaysia \\ Email: yazid3338@ukm.edu.my
}

\begin{abstract}
This paper aims to conceptually explain about the aspect of online counseling as an alternative to the new millennium service. The online counseling service offered is influenced by technological progress that people enjoy today and many aspects of the present socio-economic impacts. It will also affect the style of the environment, innovation and reform in the field of counseling. Along with these developments, age of counseling services has changed towards the cultivation of creative and innovative thinking which is able to make online counseling as a new alternative in counseling services that enables helping relationships to happen quickly and effectively via online mediums such as telephone, email, and chat room. This service is not meant to replace face-to-face psychotherapy, but is useful as an alternative resource for assistance in dealing with the problems of living with the advantages of belonging. However, there are still limitations in the implementation of online counseling including aspects of issues and ethics that need to be examined by practitioners who wish to offer this service. Thus, this paper will discuss all these vital elements of online counseling, in order to implement it in Malaysian context.
\end{abstract}

Keywords: Counseling, Helping Service, Online, Malaysia

\section{Introduction}

The rapid growth in science and technology fields especially in the field of information and communication technology has evolved and is still ongoing with great success. The society has recognized the information technology era and has indulged in it quite well. Like most of the countries around the globe, Malaysia refused to lag behind and eager to keep the pace with the development of science and technology fields especially in the field of information communication technology (ICT). The presence and convenience of the information era or digital world wave has begun to penetrate into society and has become a reality in life. In fact, the presence of information era or the wave of the digital world began to penetrate into the public generally as a package (part and partial) that cannot be separated from our lives (Mamat, 2000).

Through the development of technological advances that harp people today, they greatly affect the socio-economic aspects of a nation. It will also affect the 
environmental style, innovation and reformation in the field of counseling (Norafida \& Othman, 2000). With the existence of this virtual interactive medium, various impossible things are attainable other than allowing people to be able to exchange information and share it even within a distance. The speed of information accessed has made some people to feel comfortable using these new technologies in dealing with their daily problems. (Bahalu, 2003). Therefore, with the alignment of the changing times, the counseling service has shifted towards the cultivation of creative and innovative thinking that is capable in producing creative and innovative individuals whereby counseling services have been offered through cyberspace for instance through e-mail, telephone and chat room medium. Counseling is an aid process carried out by a counselor to a client to help in resolving problems or issues shared by the client other than developing the client's potential.

At the moment, the development of counseling services is in line with the progression of times, especially with the evolution of today's technology. This can be seen where initially counseling services are only conducted face to face between counselors and clients. However, in the present day, counseling services can be implemented and executed through various methods, including through online services, According to Oravec (2000), the role of counselors has now changed due to the influence of sophisticated telecommunications, whereby 'intimate setting' can be created. In Malaysia, online counseling services are categorized as new. However, it is a growing phenomenon and we need to take it as one of the technological outcomes. Whether we are ready or not, online counseling has become one of the counseling methods which have been practiced in our country. Although this method is said to be new in our country, but abroad, especially in the United States, Japan, the United Kingdom and Canada, the online counseling service is an aid tool that has been accepted by society. With the advancement of information technology and telecommunications, it will facilitate the implementation of counseling services without changing the original concept. As technology progresses, it is hoped that counselors will be able to master the knowledge in conducting online counseling sessions. This is because, with the mastery of knowledge about these technologies will make the counseling services to not be outdated and constantly evolving in tandem with current development. However, it is vital for the implementation of online counseling to scrutinize the possible limitations, so that it can meet the ethical requirements of counseling in professional setting.

The development of technology utilization in counseling services, especially in the United States, Canada and other countries has grown rapidly and in tandem with the ever-expanding technological developments. In fact, it is considered as a method of assistance that has been accepted by the community (Ainsworth, 2002). In the west, computer-based counseling has been in existence since the 1960s (Kraus, 2002). At the beginning, online counseling has started with the emergence of a phone-based service in psychological intervention in the United States until there was an outbreak of computer use in the handling of counseling sessions. This can be perceived through the evolution of the use of telephones in therapy which has given an early influence on the emergence of computers in the handling of counseling sessions until the emergence of online counseling.

The mental health service that first appeared on the internet was as early as in 1982 as an autonomous self-help online group. The first mental health website 
launched is "Ask Uncle Ezra" website that offers services to help individuals suffering from mental health online. The services offered are free to Cornell University students and have been operating since 1986 (Ainsworth, 2002). The launch of the website has somehow led to the rapid development of online counseling services in the west. Even online counseling services are also accepted in western societies. The evolution of the online counseling service in the west can be seen as early as in 1993, whereby Ivan Goldberg has begun in providing treatment services on online depression (Skinner \& Zack, 2004). In 1995 on the other hand, John Grohol, has developed a website on mental health advice and apart from that fees basis mental health services was also offered to the public and begin to appear online in the mid-1990s especially from the mental health advisory that has been offered to answer questions from clients with little charge payment (Ainsworth, 2002).

Sommers was the individual who provided the first internet mental health services based on fees established in 1995 and not merely providing services solely to assist the client but Sommers also strives to create another online therapeutic term (Skinner \& Zack, 2004). In 1995 also, Needham was the first practitioner to offer realtime conversations through online (Ainsworth, 2002). In the late 1990s, counselors began conducting online counseling research as one of their existing services. In fact, in the late 1990s, the International Mental Health Association was established to promote online counseling services among mental health professionals. With the advancement of technology in counseling services, the use of technology in assisting relationships has largely uses phone, email, website, chat and other applications as medium (Young, 2005). In fact, until now, studies on online counseling services are also widely practiced by western researchers for the need in helping counselors and community to understand on the phenomenon of technological advances in counseling. Chronologically, the evolution of online counseling services worldwide is summarized in the illustration of Table 1. 
The Chronology of Online Counseling Evolution in the Westvia

\begin{tabular}{cl}
\hline Year & \multicolumn{1}{c}{ Initiative/Programme } \\
\hline 1900s & $\begin{array}{l}\text { The emergence of mobile phone services in psychological } \\
\text { intervention in the United States. However, the service became } \\
\text { popular in the 20th century } \\
\text { The rapid development of telephone use in therapeutic services in } \\
\text { Europe \& US. The first service on this line is related to the suicide } \\
\text { case. It further evolves to helping children, abused women, cancer } \\
\text { patients and others. The evolution of the use of telephones in } \\
\text { therapy gives an early influence on the emergence of the use of } \\
\text { computer programs in the handling of counseling sessions. The } \\
\text { emergence of support groups on the use of online @ online } \\
\text { psychotherapy that sees the potential in online psychotherapy as } \\
\text { a therapeutic communication. } \\
\text { The success of computer as the potential initiative for discussion } \\
\text { of sensitive personal issues. } \\
\text { However, in 1997 online service was criticized by some } \\
\text { practitioners, assuming online therapy is not a real therapy } \\
\text { The first mental health website launched in 1986, the "Ask Uncle } \\
\text { Ezra" website was offered to students } \\
\text { The International Mental Health Association was established in } \\
\text { the late 1990s to promote online services among mental health } \\
\text { professionals } \\
\text { Individual email therapy was used in 1994, generally speaking that } \\
\text { the use of the internet in therapies emerged around the year of } \\
\text { 1995 in general. } \\
\text { Guidelines were created by the American Psychological } \\
\text { Association in 1997, the American Counseling Society 1999. } \\
\text { The rapid development of technology utilization in large-scale } \\
\text { help connections using phone, email, website, chat and more as } \\
\text { medium. } \\
\text { Research on online services is much sought by researchers for the } \\
\text { need in helping counselors to understanding the phenomenon of } \\
\text { technological advances in counseling. }\end{array}$ \\
\hline 1990s
\end{tabular}

\section{Concepts and Features of Online Counseling}

According to the Counselors Act (1998), counseling is a systematic help process based on psychological principles undertaken by professional counselors. This helpful relationship is carried out to bring about changes and personal development of a good and voluntary clientele throughout the lifetime. In other words, it is a more professional help modality and requires a thorough clinical and supervisory training. Generally, counseling can be defined as a process of assistance that a counselor implements to develop thought, stabilize feelings and change the behavior of clients to be more acceptable. Counseling emphasizes some confidentiality factors. Therefore, it is a process for all individuals. The counselor acts to help the client 
explore the aspects of his or her ownself and life that causes problems. This exploration will create awareness about the self, situation and options available to it (Awang, 1987; Sharf, 2000; Tang, 1989).

Murphy \& Mitchell (1998) stated that the basic concept of counseling services is the involvement of counselors and clients in the same physical space. However, this concept began to change as some counselors began to see the therapeutic potential in virtual space as an opportunity to expand their services. The internet has now become a link between counselors and clients in different spheres (Bloom, 1998; Hall, 2004; Sanders \& Rosenfield, 1998; Tait, 1999). So, the counseling process is no longer tied to a two-point meeting in a room. The online counseling service allows clients to no longer need to be in front of counselors, in the same room, and at the same time (Griffith \& Cooper, 2003).

Online counseling is a new alternative that enables a helpful relationship to happen quickly and effectively via the internet as medium. This service is not intended to replace face-to-face psychotherapy, but is useful as an alternative source for assistance in addressing life's problems. Among the forms of online counseling services offered are electronic mail, chat room, and video conference portals. The British Association for Counseling and Psychoterapy defines online counseling as an alternative counseling process that takes place in the online text-based virtual world through email or chat room (Bloom, 1998; Hall, 2004; Sanders \& Rosenfield, 1998; Tait, 1999). The official definition provided by the National Board for Certified Counselors (1997) is a professional counseling process that exists when clients and counselors are in different places but use the internet facility to communicate. The basic concept of online counseling is an interaction process between clients and counselors who are in different locations and use the internet facility to communicate (Bloom, 1998). Grohol (1999) has noted that online counseling is a new way of helping relationships, where it uses the advantages of the internet in connecting counselors and clients synchronously and asynchronously which act as the alternatives to conventional counseling approaches.

In addition, Derrig and Zeine (2005) have argued that online counseling is not a style of therapy, but it is an intermediary that can be used by counselors to assist or treat clients. Kraus (2002) has defined online counseling - which also known as 'cybercounseling' - to two parts. First, as a guiding method for clients to help them dealing with their problems that focuses on career, behavior, profession, interpersonal and emotional spiritual, where counselors use various methods, strategies and theoretical frameworks to achieve those goals. Secondly, it means a psychological construct created by professional community groups and uses such methods in interacting. In addition, Mansor (1999) stated that professional online counseling by a trained counselor should be done according to the code of ethics of counseling to achieve optimum well-being for client's life. Based on the definitions already outlined, it can be concluded that counseling can not only be done face-to-face, but can also be online and does not require clients and counselors to meet face-to-face However, this definition may change depending on current developments

Majority of researchers believe that the offer of this online counseling service takes place in the form of communications of two mechanisms which are, electronic mail and chat room (Amir, 2007; Hall, 2004; Kadir \& Mahamood, 2001; Harun, 2000; Sussman, 2004; Zainudin, 2006). The first modality is the implementation of 
counseling session through electronic mail, where the client only needs to contact the counselor through the e-mail address provided in the website. The client may email the counselor to express his / her problem, and the counselor's reply is promised to be within a stipulated period of 24 hours or 48 hours (Manhal-Baugus, 2001; Abdul Kadir \& Mahamood, 2001; Harun, 2000; Sampson et al., 1997; Sanders \& Rosenfield, 1998; Tait, 1999; Tate, et al., 2001). The second modality of service offering is through chat rooms. This chat room method occurs when clients and counselors meet and interact in cyberspace at the same time (synchronous). They can meet in chat rooms offered on websites or through 'instant messaging'. Clients can arrange and schedule timely appointments to enable both clients and counselors to interact directly during counselor's duty time. The counseling process through chat rooms can be done by contacting the counselor's website or counseling service organization, making an appointment, paying the fee (if there is any) and then attending a session in the chat room provided (Bloom, 1998; Colon, 1996; Manhal-Baugus, 2001; Ba'yah \& Yahaya, 2001; Oravec, 2000; Zainudin, 2006). In fact, with the sophistication of website software technology, it also allows users to visualize their facial expressions and voices, through the use of 'web-cam' technology that allows online counseling sessions to be conducted face-to-face.

\section{Online Counseling Process}

In the traditional context, according to Bremmer's view in 1973, the counseling process consists of eight levels as detailed in Figure 1.

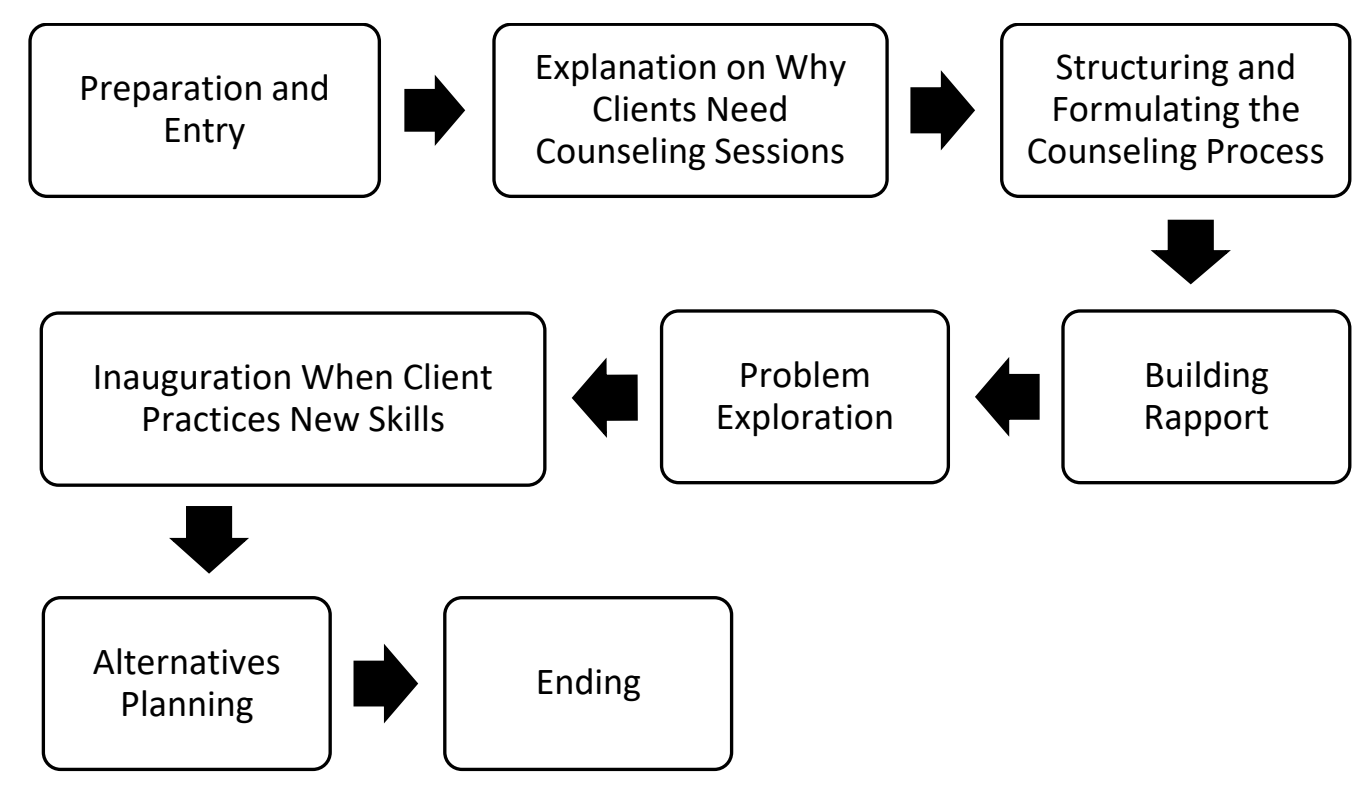

Figure 1. Bremmer's Levels of Counseling Process (1973)

Tang Cheng Yee (1989), in contrast, suggested a five-stage chain of counseling process (refer Figure 2). 


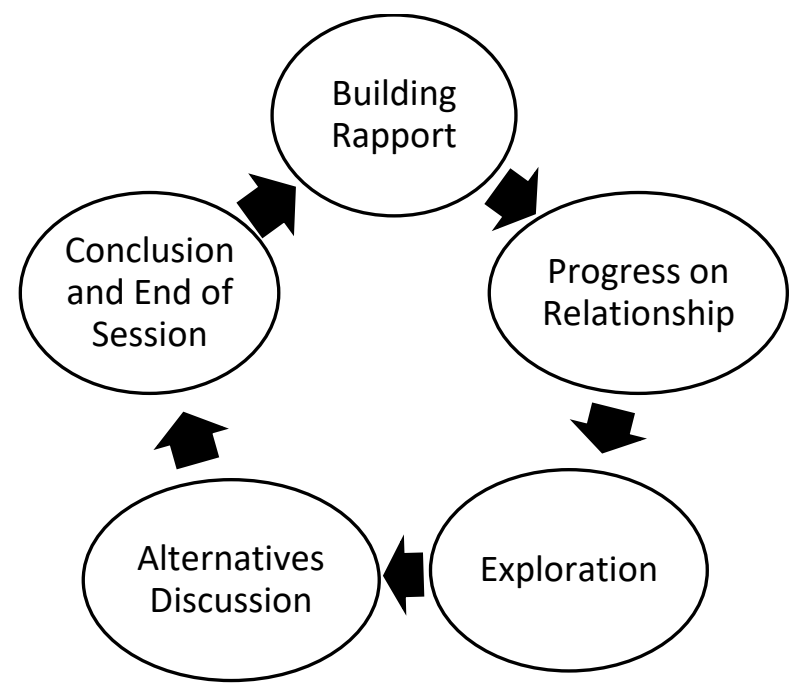

Figure 2. Stages of Counseling Process by Tang Cheng Yee (1989)

In addition, previous researchers such as Eisenberg and Delaney (1977), Lewis (1972 and Carkhuff (1969), also proposed their respective face-to-face counseling processes, which could also be applied in the implementation of online counseling. This was because many researchers stated that online 'counseling' can be implemented by adapting any model of counseling process that has a level similar to the implementation of face-to-face counseling (Griffith \& Cooper, 2003; Kasket, 2005; Murphy \& Mitchell, 1998; Sanders \& Rosenfield, 1998).

\section{Advantages of Online Counseling}

Cyberspace is the current world attraction. Many things and everyday affairs have been translated into a digital world that is much easier, cheaper and faster. Chatting or online chat activity is one of the most popular activities. Regardless of class and age rating, 'chatting' is one of the widely used internet applications. If chatting is first linked to those who engaged in chatting online for the purpose of finding new friends or simply enjoying free time, chats can be practiced in corporate worlds or other professional activities in current time.

Recognizing the need for counseling to move in line with the current scenario in the local community, online counseling is introduced to provide members with choices. Using the same mechanisms such as chatting apps, several institutions around the globe have stepped up the space for those who need to get online counseling. As such services have benefited clients or individuals who seek counseling from trained counselors virtually, through a face-to-face counseling session. Some of the features were identified to have provided the advantage of implementing online counseling services such as the services becoming more simple and convenient apart from can be performed across borders, have more privacy and security, other than focuses more on issues discussion. 


\section{Easy and Comfortable}

The online counseling session provides the clients with convenience in managing their time, energy, and day-to-day commitment in planning counseling services, especially for individuals who are likely to be bound by work and have difficulties in getting excuse to be on leave for counselling session and are bound to daily activities (Abas, 2014). In addition, with online counseling services, clients will feel more comfortable. For some clients, this service makes them to be more open-minded, where some highly embarrassing individuals will be comfortable choosing this rather than conventional method that requires them to communicate face to face with counselors.

According to Zainah et.al (2010), online counseling is one of the preferred methods for clients to obtain information and get counseling assistance in a short and speedy manner. This is because; online 'counseling' makes it easier for individuals to get professional help regardless of their locations. In fact, in terms of cost, the online counseling service does not require high finance costs when compared to face-to-face counseling. Additionally, online counseling provides space for clients with limited time to make appointments with counselors either from home or office at their convenient times. In fact, with online counseling will also save counselors' time, as well as counselors can also carry out their services from home (Aniz, 2009). Implementing online counseling sessions provides the freedom of space and the potential of creating a professional 'cyber-office' counseling setting in the future. In short, despite of the counselor's location, sessions can be conducted without any restrictions and this situation provides a space of freedom not only to the client but also to the counselor.

\section{Crossing the Border}

Driven by the rapid development of technology, online counseling services have no borders. This is because online 'counseling' benefited clients from anywhere across the borderline to seek help and counseling expertise. With advanced internet and telecommunication systems, distance, location, ocean or continent is no more an obstacle for them to obtain help and counseling services. This is very important, not to mention the issues and problems they are facing face when they are away - for any reasons such as studying, working, and so on - from family environment, close associates, and individuals who usually make up the 'support system 'and become theirs shoulders to rely on and express themselves or share problems. In other words, the implementation of 'on-line counseling' provides the best alternative for them to plan for a happier, more harmonious and prosperous life despite of their whereabouts (Aniz, 2009).

\section{Privacy and Security}

The handling of online counseling sessions is not necessarily very demanding in terms of visual but is self-sufficient with communication on WhatsApp, electronic mail and such, as those are capable of providing space for issues and problems that makes the clients feel comfortable. What's more, for more sensitive issues such as adultery, incest, pedophilia, abuse, lesbian, homosexual, drug addiction or drug trafficking, and crime, the implementation of online counseling can be discerned to preserve the privacy of the client, so that the smoothness of the session can be created when there are absence of face-to-face elements with counselors - which can cause discomfort - 
can be avoided. According to Amla et. al (2003), there are three situations where clients cannot afford to deal with counselors face-to-face. First, the client is too busy with the task that they do not have the opportunity to meet the counselor. Second, clients who are shy or having discomfort personal qualities, due to gender differences with counselors. Third, is when the client does not feel comfortable due to differences with counselors in religion, culture and ethnic background. Hence, online counseling allows clients to feel safer, have no doubt, and not feel ashamed to share any problems

As a result, with the online counseling service, clients are able to enjoy their own privacy space (Aniz, 2009). The client is free to emit tears, feel sad, angry or others without having to feel detained, embarrassed or pretentious. Hence, a more harmonious and comfortable atmosphere will have little effect on the effectiveness of counseling sessions.

\section{Focus on Issue's Discussion}

As opposed to face-to-face sessions, clients who choose the online counseling service will focus more on issues to be discussed. Usually, in a face-to-face session, the client who has been holding out on the problem for too long and many past events will tend to spill out all the issues at once, indicating the lack of focus in the partnership. But in online 'counseling' sessions, clients typically understand about the limited space (cost, time, and others.) through the communication medium of 'chat', electronic mail or telephone; Hence, the client should be more focused on sharing the issues that are most important and the most disturbing to them at that moment (Abas, 2014). In addition, in online sessions, clients are being nurtured and educated indirectly to focus more on key issues that are most disturbing to them at that moment and from time to time shift to other issues that are deemed necessary to be addressed through follow-up sessions and treatments (Aniz, 2009). This situation will definitely contribute to the success of the counseling session

\section{Limitations of Online Counseling}

The explosion of information technology or the digital wave of the world begins to penetrate the general public as a part and partial that cannot be separated from modern millennium life. The role of the counselor also changes as the influence of this sophisticated communication is able to create 'intimate setting' in the implementation of the services to be provided. The use of information technology is increasingly widespread in all areas, including in counseling services. It is no doubt that the presence of various information technology applications is able to aid and facilitate a counselor to conduct counseling sessions more effectively. However, there are limitations in the implementation of this online counseling covering the secrecy aspects, non-verbal communication, professionalism, and cross-cultural practices.

\section{Confidentiality}

The element of confidentiality is very important in a counseling session to ensure that client's information is well preserved and secured. Confidentiality is the basis in building trust in relationships between counselors and clients (Corey, 2013). Counseling conducted online does not involve face-to-face meetings between counselors and clients. In certain cases, counselors and clients do not know each 
other. This situation can pose a very serious issue from an ethical point of view, as the assurance of secrecy is uncertain (Kanani \& Regehr, 2003). Confidentiality is a component that should be addressed to counselors who use online counseling services. However, sometimes the confidentiality and security of client's information is beyond the control of a counselor; for example, when there are some irresponsible parties hacking the website or computer system of the counselor that causes the secret and identity of the client to be exposed. With today's technological sophistication, others can invade and can access all the activities that have been done (Tyler \& Sabela, 2004). The probability of such information being misused by a third party will threaten the well-being or safety of the client. Therefore, counselors should be aware of these risks when conducting online sessions; hence, precautions should be taken to address this problem such as the use of software for encryption purpose or the use of systematic passwords.

Without the assurance of secrecy, the counseling process will not be able to run smoothly. Hence, to address it, the counselor must state the code of ethics relating to confidentiality within his website, as well as requesting an informed agreement from the client first before the session commences. In addition, situations where confidentiality should be disclosed should also be notified to the clients. Finally, the assessed clients who have potential in doing something unexpected need to be proposed to attend face-to-face sessions with counselors.

\section{Non-Verbal Communication}

The absence of physical encounters between counselors and clients during online counseling sessions may lead to the failure in detecting emotional indicators such as tone of voice, facial expressions and body language. This scenario may lead to false emotional indicators exhibited by the client or misinterpretation by the counselor (because the client's body language elements are not visible). The counselor will also not be able to fully utilize his or her counseling skills in assisting clients; for example, if the client is crying or grieving, the counselor is only able to persuade and not able to do anything more. According to Matthews et al. (1990) non-verbal communication in physical presence provides more information and messages than verbal communication. The key elements in non-verbal communication such as eye contact, facial expressions, body postures, and body movements can stimulate individuals to communicate continuously. The presence of these elements in the counseling process can provide more understanding to the counselor in understanding the client's problems. Murphy et al. (1998) has stated that the absence of these non-verbal communication elements will lead the counselor to have lack of resource in interpreting the client. In fact, the possibility for counselors to misinterpret or misunderstand the meaning of an issue that the client tries to share can result in the loss of client's trust towards counselors who are trying to help.

Online counseling also disallows the counselors to detect and evaluate verbal and non-verbal signals from clients, which from those detection and evaluation usually allows the counselor to identify the client's emotional state at that time (real time). Signals such as voice tone, face ripple, body language and eye signals will not be detected because the client's physical body and movements cannot be seen online. Siegman and Mayer (1989) have mentioned that non-verbal communication involves the transfer of information and experience from one person to another, and is part of 
the communication process that occurs spontaneously and simultaneously. The presence of non-verbal communication in the conversation enabled the issue or problem that was raised comprehensively understood. In fact, without the presence of these silent communication elements the smoothness of a person's understanding in interpreting certain information will be disturbed.

In other words, the effectiveness of online counseling service can be considered as quite limited as compared to face-to-face counseling sessions. However, with the availability of facilities such as video-conference or tele-conference and video calls, the absence of non-verbal communication elements that could interfere with the smoothness of the online counseling session has begun to be resolved gradually.

\section{Professionalism Practice}

The absence of specific training given to counselors to conduct online 'sessions is the key of limitation that needs to be addressed (Chester \& Glass, 2006), as it will make them less skillful in the implementation of the session. The lack of specialized research on online counseling services has also become one of the limitations in the professionalism of counselors who offer these services, where they have limited useful information and resources to improve their services. Apart from lack of training and information, counselor's professionalism that offers online services will also be affected when many unprofessional and less-qualified counselors are involved in offering the same services. There will be possibilities that enable the counselors to engage in violation of professionalism ethics of counseling, and indirectly harm their clients.

\section{Cross-Culture}

Online counseling enables a client to get the services of any counselor of his or her choice. Counselors are also likely to handle counseling sessions with various types of client populations including international clients through electronic mails facilities such as video conferencing, video calls, and tele-conferences. The sophistication of these virtual applications allows counselors and clients of multiracial individuals and cultures to interact. Proficiency of counselors will be tested with different clients from disparate cultures and beliefs as they may all lead to the failure of counselors in understanding clients' issues (Manhal-Baugus, 2001; Sampson et al., 1997). The failure of counselors to understand the diversity of cross-cultural issues will result in the effectiveness of the online offered services to be impaired. Hence, online counselors should constantly update their knowledge, personal awareness, sensitivity, and crosscultural skills to ensure that the services rendered are always relevant and effective for all levels of clients despite of their background.

\section{Conclusion}

In general, there is a lack of trust in counseling services or the community is still uncertain for the counselors to be the best individuals in sharing their problems and finding the best solutions to their life-threatening issues. In this regard, online counseling is able to alter the stigma and concerns of the public on counseling services. The availability of online counseling services has given space to new clients for counseling sessions. However, in addition to the advantages possessed, the counselor intending to offer this service should also examine the potential limitations in its 
implementation. Furthermore, it is the responsibility of the counselor to ensure that clients can be optimally assisted without any violation of the professionalism ethics that has been set.

The globalization era has opened extensive online communication boundaries, and this also provides room for the improvement of the provision of counseling services to the community. Given the limitations and aspects that need to be addressed, counseling profession today should take the opportunity to adapt the potential of online services as an alternative to conventional methods of face-to-face counseling g-mail service delivery.

This research is expected to be an important preliminary initiative to trigger further studies related to online counselling services in a local context. The outcome of this research will be important to researchers who are interested in the field of online counselling services. Given the limitations of online counseling research, it is important to carry out this research as it will be a guide for all parties, especially counselors, training institutions, local universities, counseling associations and other professionals in contributing to the training and expertise in providing online counseling services for clients to meet the needs of services in line with the development of technology nowadays.

\section{References}

Abas, M. K. J. (2014). Online Counseling. http://ustazkhirjohari.blogspot.com/2014/04/kaunseling-secara-online.html. [10 Mei 2015].

Kadir, A. N. B., \& Mahamood, Y. (2001). Wellness Psychology: E-Counseling as an Immediate Method of Assistance in Solving Psychological Problems. Journal of Psychology and Human Development, 17, 225-242.

Ainsworth, M. 2002. E-Therapy: History and Survey. http://www.metanoia.org/imhs/history.html. [12 Jun 2017].

Amla, M. S., Zuria, M., \& Salleh, A. (2003). School Guidance and Counseling. Bangi: UKM Press.

Aniz, A. (2009). Advantages of Online Counseling Session. http://www.anizanwar.com/kelebihan-menjalani-sesi-kaunseling-secaraonline. [10 Mei 2015].

Awang, A. (2007). E-counseling and community development. Paper presented at the $24^{\text {th }}$ National Level Counseling Workshop Hotel Equatorial, Bangi, Selangor.

Awang, A. (1987). Theory and Psychotherapy Practice. Pulau Pinang: USM Press.

Bahalu, R. (2003). Multimedia: The Latest Trends Achieve the 21st Century of Education Needs. Paper Presented in the Latest Trends of Information and Communication Technology (ICT), Intekma, Shah Alam.

Bloom, J. W. (1998). The ethical practice of webcounselling. British Journal of Guidance and Counselling, 26, 1, 53-59.

Chester, A., \& Glass, C. (2006). Online Counselling: A descriptive analysis of therapy services on the Internet. British Journal of Guidance and Counselling.

Colon, Y. (1996). Chatter(er) ing through the fingertips: doing group therapy online. Journal of Feminist Theory, 9, 205-215.

Derrig, K., \& Zein, F. (2005). Online Therapy: The Therapist Guide to Expanding Your Practice. New York, NY: Norton. 
Gerald, C. (2013). Theory and Practice of Counseling and Psychotherapy.

Gresle, C., \& Lejoyeux, M. (2011). Phenomenology of Internet Addiction. IN: Price, Ho $(\mathrm{Ed})$.

Griffith, M. D, \& Cooper, G. (2003). Online therapy: Implication for problem gamblers and clinicians. British Journal of Guidance and Counselling, 31, 1, 113-135.

Grohol, J. M. (1999). Definition \& Scope of E-Therapy. http://psychcentral.com/best/best3.html. [11 Mei 2015].

Hall, P. (2004). Online psychosexual therapy: A summary of pilot study findings. Sexual and Relationship Therapy, 19, 2, 167-178.

Harun, L. M. (2000). E-mail therapy: a case study. Paper presented in the Seminar of Education and ICT in the new millennium, Park Royal, Kuala Lumpur.

Kanani, K., \& Regehr, C. (2003). Clinical, Ethical, and Legal Issues In E-

Therapy. Families in Society, 84(2), 155-162.

Kasket, E. (2003). Online Counselling. Existential Analysis, 14, 1, 60-74.

Kraus, R. (2002). Online Counselling: A Handbook for Mental Health Professional. CA: Elsevier Academic Press.

Liu, V.T., \& Potenza, M.N. (2010). Problematic Internet Use: Clinical Aspects. Aboujaoude, E., \& Koran, LM (ed.) Impulse Control Disorders.

Mansor, A. T. (1999). E-Counseling. http://www.anglefire.com/ma4/mcch/doc. [5 Jun 2015].

Manhal-Baugus, M. (2001). E-Therapy: Practical, Ethical and Legal Issues. Cyberpsychology \& Behavior, 4, 5, 551-563.

Murphy, L. J., \& Mitchell, D. L. (1998). When writing helps to heal: e-mail as therapy. British Journal of Guidance and Counselling, 26, 21-32.

Norafida, I., \& Othman, I. (2000). E-learning live (live e-learning) in virtual learning. Paper Presented at Konvensyen Pendidikan, UTM 2000.

Mamat, N. M. (2000). Era of Information from the Islamic Perspectives. Pemikir, 1526.

Oravec, J. A. (2000). Online counselling and the Internet: Perspectives for Mental Health Care Supervision and Education. Journal of Mental Health, 9, 2, 121-136.

Oravec, J. A. (2000). Internet and computer technology hazards: perspective for family counseling. British Journal of Guidance \& Counselling, 28, 3, 309-324.

Sampson, J., Kolodinsky, R., \& Greeno, B. P. (1997). Counselling in the information highway: future possibilities and potential problems. Journal of Counselling and Development, 75, 205-221.

Sanders, P., \& Rosenfield, M. (1998). Counselling at a distance: Challenges and new initiatives. British Journal of Guidance \& Counselling, 26, 1, 5-10.

Sharf, R. S. (2000). Theories of Psychotherapy \& Counseling: Concepts and Cases. USA: Brooks/Cole.

Siegman, A. W., \& Mayer, G. (1989). Non-verbal Behavior and Communications. New York: Hillsdale.

Skinner, A., \& Zack, J. S. (2004). Counseling and the Internet. American Behavioral Scientist, 48. 434-446.

Sussman, R. J. (2004). Counselling over the internet: Benefits and challenges in the use of new technologies. Cyberbytes: Highlighting Compelling Uses of Technology in Counseling. ERIC. [27 April 2016]. 
Tang, C. Y. (1989). Guidance and Counseling: For Primary and Secondary Schools. Kuala Lumpur: Kumpulan Budiman Sdn. Bhd.

Tait, A. (1999). Face-to-face and at a distance: The mediation of guidance and counselling through the new technologies. British Journal of Guidance \& Counselling, 27, 1, 113-123.

Tate, D. F., Wing, R. R, \& Winett, R. A. (2001). Using internet technology to deliver a behavioral weight loss program. Journal of the American Medical Association, 285, 1172-1177.

Tyler, M. J., \& Sabella, R. A. (2004). Using technology to improve counseling practice: A primer for the 21st century. Alexandria, VA: American Counseling Association.

Young, K. S. (2005). An Empirical Examination of Client Attitudes towards Online Counselling. CyberPsychology \& Behavior, 8:172-177.

Zainudin, Z. N. (2012). Concepts and Features of E-counseling. http://www.e kaunseling.50webs.com/KONSEP.pdf. [June 5, 2015].

Zainudin, Z. N. (2006). Virtual Relations Relations: A Research. Paper Presented at the Counselor Board Conference, Hotel Legend, Kuala Lumpur.

Zainudin, Z. N., \& Harun, L. M. (2006). Virtual Helping Relationships: A Research. Paper Presented in the National Counseling Seminar 15-16 December 2006 at Hotel Legend, Kuala Lumpur Organized by Lembaga Kaunselor Malaysia.

Zainah, A. Z., Rohany, N., \& Fatimah, Y. (2010). Perception towards Online Counseling among Counselor In Malaysia, Procedia Social and Behavioral Sciences 5 (2010): 585-589. 